\title{
Surgical treatment of ischemic mitral regurgitation might not influence ventricular remodeling
}

Yoshiharu Enomoto, MD

Joseph H. Gorman III, MD

Sina L. Moainie, MDa

T. Sloane Guy, MD

Benjamin M. Jackson, MD

Landi M. Parish, $\mathrm{SB}^{\mathrm{a}}$

Theodore Plappert, $\mathrm{CVT}^{\mathrm{b}}$

Ahmad Zeeshan, MD

Martin G. St. John-Sutton, MBBS ${ }^{b}$

Robert C. Gorman, MDa
From the Harrison Department of Surgical Research $^{\mathrm{a}}$ and the Department of Medicine, ${ }^{\mathrm{b}}$ University of Pennsylvania School of Medicine, Philadelphia, Pa.

Supported by grants HL71137, HL63954, and HL73021 from the National Heart, Lung, and Blood Institute, National Institutes of Health, Bethesda, Md; a grant from the Mary L. Smith Charitable Trust, Newtown Square, $\mathrm{Pa}$; and the W. W. Smith Charitable Trust, Newtown Square, Pa.

Read at the Eighty-fourth Annual Meeting of The American Association for Thoracic Surgery, Toronto, Ontario, Canada, April 25-28, 2004.

Received for publications May 25, 2004; revisions received Sept 29, 2004; accepted for publication Sept 30, 2004.

Address for reprints: Robert C. Gorman, MD, Department of Surgery, 6 Silverstein Pavilion, Hospital of the University of Pennsylvania, 3400 Spruce St, Philadelphia, PA 19104 (E-mail: gormanr@uphs.upenn.edu).

J Thorac Cardiovasc Surg 2005;129:504-11 $0022-5223 / \$ 30.00$

Copyright (c) 2005 by The American Association for Thoracic Surgery

doi:10.1016/j.jtcvs.2004.09.035
Objectives: Surgical treatment for ischemic mitral regurgitation has become more aggressive. However, no clinical study has demonstrated that surgical correction of chronic ischemic mitral regurgitation improves survival. We used 4 well-developed ovine models of postinfarction left ventricular remodeling to test the hypothesis that ischemic mitral regurgitation does not significantly contribute to postinfarction left ventricular remodeling.

Methods: Infarction of $21 \%$ to $24 \%$ of the left ventricular mass was induced by means of coronary ligation in 77 sheep. Infarctions varied only by anatomic location in the left ventricle: anteroapical, $\mathrm{n}=26$; anterobasal, $\mathrm{n}=16$; laterobasal, $\mathrm{n}=9$; and posterobasal, $\mathrm{n}=20$. Six additional sheep had ring annuloplasty before posterobasal infarction. End-systolic and end-diastolic left ventricular volume, end-systolic muscle-to-cavity area ratio, left ventricular sphericity, ejection fraction, and degree of ischemic mitral regurgitation, as determined by means of quantitative echocardiography, were assessed before infarction and at 2, 5, and 8 weeks after infarction.

Results: All infarcts resulted in significant postinfarction remodeling and decreased ejection fraction. Anteroapical infarcts lead to left ventricular aneurysms. Only posterobasal infarcts caused severe and progressive ischemic mitral regurgitation. Remodeling because of posterobasal infarcts was not more severe than that caused by infarcts at other locations. Furthermore, prophylactic annuloplasty prevented the development of mitral regurgitation after posterobasal infarction but had no effect on remodeling.

Conclusion: The extent of postinfarction remodeling is determined on the basis of infarct size and location. The development of ischemic mitral regurgitation might not contribute significantly to adverse remodeling. Ischemic mitral regurgitation is likely a manifestation rather than an important impetus for postinfarction remodeling.

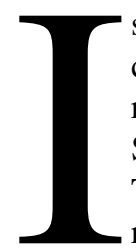

schemic mitral regurgitation (IMR) is mitral regurgitation (MR) that is caused by a myocardial infarction (MI) and subsequent infarction-induced remodeling. ${ }^{1}$ IMR likely affects 1.2 to 2.1 million patients in the United States, with more than 400,000 patients having moderate-to-severe MR. ${ }^{1}$ These numbers are expected to progressively increase as the population rapidly ages and more patients survive acute MI.

It is widely believed that the surgical correction of IMR is beneficial, and most of the current literature has focused on whether valve repair or replacement is 
preferable. ${ }^{2,3}$ However, scant data exist to support the commonly held assumption that elimination of IMR improves survival or affects the remodeling process. In fact, the most credible data would suggest that the surgical treatment of IMR influences long-term survival very little. ${ }^{2-4}$

These clinical data, as well as experimental data from our laboratory, ${ }^{5}$ have led us to hypothesize that IMR is a manifestation of infarction-induced remodeling that does not significantly contribute to the process that leads to progressive ventricular dilatation and associated congestive heart failure.

Four ovine models of MI were used to test this hypothesis. Infarcts in all 4 models are similarly sized ${ }^{6-10}$ but involve different regions of the left ventricle (LV): anteroapical, anterobasal, laterobasal, and posterobasal. Only the posterobasal infarct model reliably results in significant IMR. ${ }^{7,9}$ The outcome of remodeling in a group of animals having an untreated posterobasal infarct was compared with remodeling induced by anteroapical, anterobasal, and laterobasal infarcts. The untreated posterobasal infarct group was also compared with a group of animals that had a ring annuloplasty device placed before posterobasal infarction with the intent of preventing the development of IMR (the posterobasal with annuloplasty [PBA] group). If IMR influences the remodeling process, the untreated posterobasal infarct group is expected to have more severe changes in LV size and shape than the other 4 groups of animals.

\section{Methods}

\section{Infarction Models and Experimental Groups}

Infarction of $21 \%$ to $24 \%$ of the LV mass was induced by means of coronary ligation in 77 sheep. Infarctions varied only by anatomic location in the LV. An anteroapical infarction involving $22 \% \pm 3 \%$ of the LV mass was created in 26 animals by ligating the left anterior descending artery and its second diagonal branch $40 \%$ of the distance from the apex to the base of the heart. ${ }^{6}$ This infarction reproducibly results in large LV aneurysms after 8 weeks of remodeling. Sixteen sheep had an anterobasal infarction involving $24 \% \pm 2 \%$ of the $\mathrm{LV}$ that was produced by ligating the first and second diagonal branches of the left anterior descending artery. ${ }^{7,8}$ Nine animals had a laterobasal infarction produced by ligating the first and second marginal branches of the circumflex artery. This infarct involves $23 \% \pm 3 \%$ of the LV mass. ${ }^{9}, 10$ Twenty animals had a posterobasal infarction produced by ligating the second and third obtuse marginal branches of the circumflex coronary artery, which involves $21 \% \pm 4 \%$ of the LV mass and routinely results in IMR. ${ }^{9,11}$ Finally, 6 additional sheep had a ring annuloplasty before posterobasal infarction. ${ }^{5}$

\section{Surgical Protocol}

Dorset male hybrid sheep (Animal Biotech Industries, Doylestown, Pa) weighing 35 to $40 \mathrm{~kg}$ were used for this study. Animals were treated under an experimental protocol approved by the University of Pennsylvania's Institutional Animal Care and Use Committee and in compliance with the "Guide for Care and Use of
Laboratory Animals." Anesthesia was induced with thiopental sodium (10-15 mg/kg intravenously) and the animals were intubated. Anesthesia was maintained with isoflurane (1.5\%-2\%) and oxygen. Under aseptic conditions, all animals underwent left thoracotomy. Polypropylene snares were loosely placed around the appropriate coronary arteries. Seventy-one animals underwent closure of the thoracotomy and recovery. Six animals underwent placement of a 24-mm mitral annuloplasty ring (Carpentier-Edwards Physio, Edwards Lifesciences, Irvine, Calif) with standard cardiac surgical techniques after snares were placed to produce a posterobasal infarct. After termination of cardiopulmonary bypass, these animals underwent closure of the thoracotomy and recovered. $^{5}$

\section{Baseline Data and Infarction}

Ten to 14 days after initial instrumentation, the sheep were again anesthetized. The surface electrocardiogram and arterial blood pressure were continuously monitored (Sonometrics Inc, London, Ontario, Canada) and recorded during all data collection procedures. A high-fidelity pressure transducer (SPC-350; Millar Instruments Inc, Houston, Tex) was inserted through a femoral artery into the LV for continuous LV pressure monitoring (78534c monitor; Hewlett-Packard, Palo Alto, Calif). A pulmonary artery catheter (131-h, 7F; Baxter Healthcare Corp, Deerfield, Ill) was placed; thermodilution cardiac output was measured in triplicate at each time point for each animal. Animals were disconnected from the ventilator and atrially paced at 120 beats/min during data collection. After baseline hemodynamic and echocardiographic data were recorded, the subcutaneous snares were exposed, tightened, and tied to produce infarction. Each animal received magnesium sulfate, bretylium tosylate (INN: bretylium tosilate), and lidocaine before infarction. Hemodynamic and echocardiographic data were again collected 30 minutes after infarction.

\section{Echocardiography}

Quantitative, 2-dimensional, subdiaphragmatic echocardiograms were obtained before infarction and at 30 minutes and 2, 5, and 8 weeks after infarction. A sterile midline laparotomy (or a right or left subcostal incision) was made, and subdiaphragmatic, quantitative, 2-dimensional echocardiographic images were obtained with a $5-\mathrm{MHz}$ probe $(77020 \mathrm{~A}$, Hewlett-Packard). Images were recorded on VHS videotape at $30 \mathrm{~Hz}$ (Panasonic AG-6300 VHS Recorder). LV short-axis images at 3 levels (the tips of the papillary muscles, the bases of the papillary muscles, and the apex) and 2 orthogonal long-axis views were recorded. Previous reports have validated the reproducibility and effectiveness of this technique for evaluating LV remodeling in sheep. ${ }^{5,12,13} \mathrm{LV}$ endsystolic volume (LVESV) and LV end-diastolic volume (LVEDV) were calculated by using Simpson's rule. ${ }^{14}$ Ejection fraction was calculated from LVESV and LVEDV. End-systolic muscle-tocavity area ratio (ESMCAR) was also determined at each time point. Ventricular sphericity at end systole was assessed as the ratio of LVESV to the volume of a sphere with a diameter equal to the LV long-axis dimension. This ratio approaches unity as the ventricle becomes more spherical. All measured echocardiographic indexes of remodeling were normalized to their baseline values. The degree of MR was determined quantitatively by assessing the area of the regurgitant jet as a percentage of left atrial 
TABLE 1. Hemodynamic data for 5 ovine myocardial infarction models

\begin{tabular}{lccrr}
\hline Group & MAP & LVEDP & \multicolumn{1}{c}{ CVP } & CO \\
\hline Anteroapical & & & & \\
Preinfarct & $75 \pm 7$ & $1.7 \pm 1.0$ & $9.6 \pm 2.6$ & $2.4 \pm 0.7$ \\
Postinfarct & $63 \pm 6$ & $8.2 \pm 3.5^{*}$ & $11.9 \pm 3.2$ & $2.3 \pm 0.9$ \\
Week 2 & $69 \pm 6$ & $6.4 \pm 5.7^{*}$ & $8.2 \pm 2.5$ & $2.0 \pm 0.8$ \\
Week 5 & $69 \pm 4$ & $6.0 \pm 1.9^{*}$ & $7.6 \pm 2.1$ & $1.9 \pm 0.4$ \\
Week 8 & $71 \pm 5$ & $5.7 \pm 2.8^{*}$ & $8.3 \pm 3.0$ & $1.6 \pm 0.7$ \\
Anterobasal & & & & \\
Preinfarct & $65 \pm 5.6$ & $1.7 \pm 1.0$ & $4.4 \pm 0.9$ & $2.9 \pm 0.8$ \\
Postinfarct & $59 \pm 4.0$ & $5.7 \pm 2.8^{*}$ & $5.2 \pm 2.1$ & $2.3 \pm 0.8$ \\
Week 2 & $69 \pm 2.1$ & $6.0 \pm 1.9^{*}$ & $5.0 \pm 2.3$ & $2.8 \pm 0.9$ \\
Week 5 & $71 \pm 6.5$ & $6.6 \pm 2.3^{*}$ & $6.1 \pm 1.9$ & $2.7 \pm 0.7$ \\
Week 8 & $66 \pm 2.3$ & $8.2 \pm 3.5^{*}$ & $5.9 \pm 2.7$ & $2.4 \pm 0.9$ \\
Laterobasal & & & & \\
Preinfarct & $69 \pm 6$ & $1.8 \pm 1.1$ & $10.2 \pm 3.1$ & $2.5 \pm 0.5$ \\
Postinfarct & $69.9 \pm 3.0^{*}$ & $13.3 \pm 2.2$ & $2.4 \pm 0.7$ \\
Week 2 & $72 \pm 5$ & $6.5 \pm 5.8$ & $11.4 \pm 3.0$ & $2.2 \pm 0.9$ \\
Week 5 & $74 \pm 3$ & $6.4 \pm 1.8^{*}$ & $12.1 \pm 2.4$ & $2.0 \pm 0.9$ \\
Week 8 & $70 \pm 5$ & & $11.6 \pm 3.2$ & $1.8 \pm 0.8$ \\
Posterobasal & & & \\
Preinfarct & $72 \pm 7$ & $12.1 \pm 4.7$ & $3.5 \pm 1.1$ \\
Postinfarct & $63 \pm 4$ & $12.7 \pm 9.5$ & $3.9 \pm 1.2$ \\
Week 2 & $69 \pm 4$ & $5.6 \pm 5.7$ & $12.6 \pm 5.0$ & $3.7 \pm 0.7$ \\
Week 5 & $71 \pm 5$ & $6.6 \pm 1.4$ & $10.8 \pm 4.4$ & $3.7 \pm 1.0$ \\
Week 8 & $73 \pm 4$ & $5.0 \pm 1.3$ & $11.0 \pm 4.3$ & $3.7 \pm 0.9$ \\
Posterobasal with annuloplasty & & & \\
Preinfarct & $74 \pm 8$ & $6.0 \pm 6.3$ & $13.6 \pm 6.8$ & $3.7 \pm 1.3$ \\
Postinfarct & $62 \pm 3$ & $6.0 \pm 4.6$ & $11.0 \pm 5.1$ & $3.3 \pm 1.0$ \\
Week 2 & $70 \pm 5$ & $7.0 \pm 9.0$ & $10.0 \pm 8.6$ & $2.8 \pm 1.4$ \\
Week 5 & $75 \pm 4$ & $14.6 \pm 5.0$ & $3.4 \pm 1.0$ \\
Week 8 & $73 \pm 4$ & & $3.2 \pm 1.3$ \\
\hline
\end{tabular}

$M A P$, Mean arterial pressure; $L V E D P$, left ventricular end-diastolic pressure; CVP, central venous pressure; $C O$, cardiac output.

*Significant difference from before infarction $(P<.05)$.

area in the apical 4-chamber view. The following grading was used: grade 1 , less than $20 \%$; grade $2,20 \%$ to $40 \%$; grade $3,40 \%$ to $60 \%$; and grade 4 , greater than $60 \%$. $^{15}$

\section{Follow-up Studies}

Hemodynamic and echocardiographic data were collected at 30 minutes and 2, 5, and 8 weeks after infarction. After the 9-week study, the animals were put to death. The heart was excised and photographed to confirm infarction size and location.

\section{Statistics}

Measurements are reported as means \pm SEM. Between-group differences in all continuous dependent variables (ie, all but MR grade) were compared by analysis of variance for repeated measures. If analysis of variance revealed significant differences, the Student $t$ test with the Bonferroni correction was used to assess differences between groups at specific time points after infarction (SPSS, Chicago, Ill). Differences in the degree of MR between groups were assessed by the nonparametric Kruskal-Wallis test. The Mann-Whitney test with the Bonferroni correction was used to evaluate the differences in MR between any 2 groups at specific time points.

\section{Results \\ Hemodynamic Data}

Hemodynamic data are presented in Table 1. No significant differences in LV end-diastolic pressure, central venous pressure, pulmonary artery diastolic pressure, mean arterial pressure, or cardiac output were observed between groups.

\section{Echocardiographic Data}

Echocardiographic data are summarized in Table 2. As expected, the posterobasal group had progressive and moderate-to-severe MR (2.8 \pm 0.2$)$ after 8 weeks. IMR was effectively prevented by the ring annuloplasty in the PBA group. None of the remaining 3 groups (anteroapical, anterobasal, and laterobasal) had significant IMR as a result of remodeling (Figure 1). All the groups, irrespective of infarct location or annuloplasty placement, had adverse infarction- 
TABLE 2. Echocardiographically determined indexes of infarction induced remodeling in 5 ovine infarction models

\begin{tabular}{|c|c|c|c|c|c|c|}
\hline Group & MR & LVESV & LVEDV & ESMCAR & Sphericity & EF \\
\hline \multicolumn{7}{|l|}{ Anteroapical } \\
\hline Preinfarct & $0.34 \pm 0.12$ & $1.00 \pm 0.00$ & $1.00 \pm 0.00$ & $1.00 \pm 0.00$ & $1.00 \pm 0.00$ & $1.00 \pm 0.00$ \\
\hline Postinfarct & $0.96 \pm 0.25$ & $1.30 \pm 0.07^{*}$ & $1.16 \pm 0.05^{*}$ & $1.17 \pm 0.05^{*}$ & $0.89 \pm 0.05^{*}$ & $1.29 \pm 0.41$ \\
\hline Week 2 & $0.46 \pm 0.20$ & $1.87 \pm 0.18^{*}$ & $1.42 \pm 0.11^{*}$ & $0.90 \pm 0.05$ & $1.03 \pm 0.07$ & $0.98 \pm 0.33$ \\
\hline Week 5 & $0.36 \pm 0.24$ & $2.06 \pm 0.16^{*}$ & $1.56 \pm 0.11^{*}$ & $0.88 \pm 0.07^{*}$ & $1.17 \pm 0.08^{*}$ & $0.87 \pm 0.36$ \\
\hline Week 8 & $0.60 \pm 0.20$ & $2.38 \pm 0.12^{*}$ & $1.78 \pm 0.07^{*}$ & $0.86 \pm 0.06^{*}$ & $1.20 \pm 0.06^{*}$ & $0.83 \pm 0.32^{*}$ \\
\hline \multicolumn{7}{|l|}{ Anterobasal } \\
\hline Preinfarct & $0.47 \pm 0.12$ & $1.00 \pm 0.00$ & $1.00 \pm 0.00$ & $1.00 \pm 0.00$ & $1.00 \pm 0.00$ & $1.00 \pm 0.00$ \\
\hline Postinfarct & $1.06 \pm 0.25$ & $1.14 \pm 0.10$ & $1.14 \pm 0.07^{*}$ & $0.83 \pm 0.09^{*} \ddagger$ & $0.92 \pm 0.08$ & $1.20 \pm 0.15$ \\
\hline Week 2 & $0.77 \pm 0.20$ & $1.63 \pm 0.14^{*}$ & $1.43 \pm 0.11^{*}$ & $0.85 \pm 0.05^{*}$ & $1.21 \pm 0.07^{*}$ & $0.92 \pm 0.13$ \\
\hline Week 5 & $0.67 \pm 0.24$ & $1.88 \pm 0.19^{*}$ & $1.63 \pm 0.16^{*}$ & $0.74 \pm 0.07^{*}$ & $1.35 \pm 0.10^{*}$ & $0.86 \pm 0.12$ \\
\hline Week 8 & $0.70 \pm 0.20$ & $2.04 \pm 0.24^{*}$ & $1.64 \pm 0.11^{*}$ & $0.75 \pm 0.06^{*}$ & $1.35 \pm 0.13^{*} \ddagger$ & $0.76 \pm 0.09 *$ \\
\hline \multicolumn{7}{|l|}{ Laterobasal } \\
\hline Preinfarct & $0.17 \pm 0.08$ & $1.00 \pm 0.00$ & $1.00 \pm 0.00$ & $1.00 \pm 0.00$ & $1.00 \pm 0.00$ & $1.00 \pm 0.00$ \\
\hline Postinfarct & $0.28 \pm 0.22$ & $0.97 \pm 0.04 \dagger t \|$ & $1.04 \pm 0.07 \|$ & $0.92 \pm 0.03^{*} \ddagger$ & $0.91 \pm 0.04^{*}$ & $1.10 \pm 0.07$ \\
\hline Week 2 & $0.50 \pm 0.25$ & $1.45 \pm 0.20^{*}$ & $1.30 \pm 0.07^{*}$ & $0.85 \pm 0.07^{*}$ & $0.89 \pm 0.15$ & $0.69 \pm 0.11^{*}$ \\
\hline Week 5 & $0.22 \pm 0.12$ & $1.72 \pm 0.11^{*}$ & $1.48 \pm 0.11^{*}$ & $0.90 \pm 0.10^{*}$ & $1.07 \pm 0.09$ & $0.78 \pm 0.07^{*}$ \\
\hline Week 8 & $0.32 \pm 0.23$ & $1.91 \pm 0.13^{*} \ddagger$ & $1.59 \pm 0.08^{*} \ddagger$ & $0.83 \pm 0.05^{*}$ & $1.37 \pm 0.08^{*} \ddagger$ & $0.75 \pm 0.06^{*}$ \\
\hline \multicolumn{7}{|l|}{ Posterobasal } \\
\hline Preinfarct & $0.40 \pm 0.12$ & $1.00 \pm 0.00$ & $1.00 \pm 0.00$ & $1.00 \pm 0.00$ & $1.00 \pm 0.00$ & $1.00 \pm 0.00$ \\
\hline Postinfarct & $1.98 \pm 0.20^{*} \dagger \ddagger \S$ & $1.05 \pm 0.09$ & $1.18 \pm 0.04^{*}$ & $0.87 \pm 0.06^{*} \ddagger$ & $0.90 \pm 0.09$ & $1.06 \pm 0.08$ \\
\hline Week 2 & $2.41 \pm 0.17^{*} \dagger \ddagger \S$ & $1.51 \pm 0.13^{*}$ & $1.36 \pm 0.07^{*}$ & $0.78 \pm 0.05^{*}$ & $1.19 \pm 0.11^{*}$ & $0.92 \pm 0.06$ \\
\hline Week 5 & $2.35 \pm 0.27^{*} † \ddagger \S$ & $1.57 \pm 0.20^{*}$ & $1.45 \pm 0.10^{*}$ & $0.72 \pm 0.07^{*}$ & $1.17 \pm 0.14$ & $0.64 \pm 0.08^{*}$ \\
\hline Week 8 & $2.83 \pm 0.21^{*} † \ddagger \S$ & $2.18 \pm 0.18^{*}$ & $1.76 \pm 0.10^{*}$ & $0.67 \pm 0.04^{*} † \ddagger \S$ & $1.43 \pm 0.10^{*} \ddagger$ & $0.74 \pm 0.07^{*}$ \\
\hline \multicolumn{7}{|c|}{ Posterobasal with annuloplasty } \\
\hline Preinfarct & $0.60 \pm 0.24$ & $1.00 \pm 0.00$ & $1.00 \pm 0.00$ & $1.00 \pm 0.00$ & $1.00 \pm 0.00$ & $1.00 \pm 0.00$ \\
\hline Postinfarct & $0.80 \pm 0.20 \|$ & $1.17 \pm 0.07^{*}$ & $1.08 \pm 0.03^{*}$ & $0.74 \pm 0.04^{*} \ddagger$ & $1.03 \pm 0.09$ & $0.86 \pm 0.11$ \\
\hline Week 2 & $0.40 \pm 0.24 \|$ & $1.58 \pm 0.12^{*}$ & $1.33 \pm 0.08^{*}$ & $0.76 \pm 0.12^{*}$ & $1.37 \pm 0.07^{*}$ & $0.71 \pm 0.05^{*}$ \\
\hline Week 5 & $0.40 \pm 0.24 \|$ & $1.85 \pm 0.18^{*}$ & $1.53 \pm 0.09^{*}$ & $0.72 \pm 0.12^{*}$ & $1.43 \pm 0.11^{*}$ & $0.72 \pm 0.09 *$ \\
\hline Week 8 & $0.60 \pm 0.24 \|$ & $2.05 \pm 0.28^{*}$ & $1.68 \pm 0.14^{*}$ & $0.65 \pm 0.10^{*} \dagger \ddagger \S$ & $1.43 \pm 0.06^{*} \ddagger$ & $0.75 \pm 0.14^{*}$ \\
\hline
\end{tabular}

$M R$, Mitral regurgitation; $L V E S V$, left ventricular end-systolic volume; $L V E D V$, left ventricular end-diastolic volume; ESMCAR, end-systolic muscle-to-cavity area ratio; $E F$, ejection fraction. LVESV, LVEDV, ESMCAR, sphericity, and EF are normalized to baseline.

$* P \leq .05$ within groups when compared with the preinfarct subset.

$\dagger P \leq .05$ between groups when compared with the anterobasal group.

$\ddagger P \leq .05$ between groups when compared with the anteroapical group.

$\S P \leq .05$ between groups when compared with the laterobasal group.

$\| P \leq .05$ between groups when compared with the posterobasal group.

induced remodeling, as manifest by profound ventricular enlargement and shape changes.

In all 5 groups, LVESV and LVEDV increased significantly, reflecting postinfarction remodeling over the 8-week period (Figure 2); ejection fraction also decreased in all groups (Table 2). The only significant differences in LVESV and LVEDV between groups at 8 weeks occurred between the laterobasal infarct group (LVESV, $1.91 \pm 0.13$; LVEDV, $1.59 \pm 0.08$ ) and the anteroapical infarct group (LVESV, $2.38 \pm 0.12$; LVEDV, $1.78 \pm 0.07 ; P<.05$ ). No differences in these parameters were observed between the other groups at 8 weeks (Table 2).

With regard to ventricular shape, all groups had significant increases in ventricular sphericity (Figure 3 ) and decreases in ESMCAR (Figure 4) as a result of remodeling.
The anteroapical group was significantly less spherical than the basilar infarct groups (anterobasal, laterobasal, posterobasal, and PBA) at 8 weeks. No difference in sphericity could be established between any of the 4 groups having a basilar infarct. ESMCAR was significantly less at 8 weeks in the posterobasal and PBA groups than in the anteroapical, anterobasal, and laterobasal groups. However, there was no difference in ESMCAR between the posterobasal and PBA groups.

\section{Discussion}

The extent of ventricular remodeling is a powerful prognosticator for longevity in patients who survive an acute MI. ${ }^{16}$ The data from this study strongly suggest that infarct size and, to a lesser degree, infarct location determine the out- 


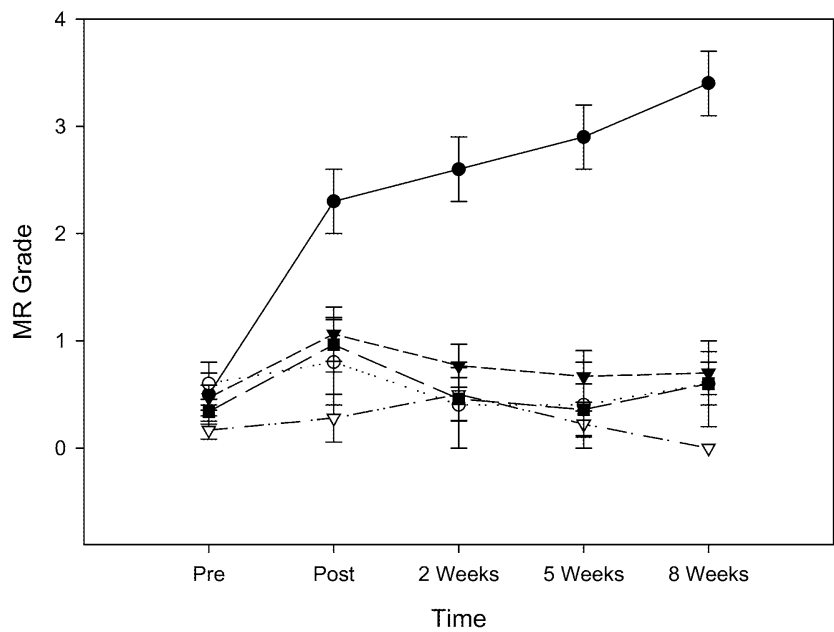

\begin{tabular}{|c|c|}
\hline 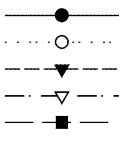 & $\begin{array}{l}\text { Posterobasal Infarct, No Treatment } \\
\text { Posterobasal Infarct, Annuloplasty } \\
\text { Anterobasal Infarct } \\
\text { Anterolateral Infarct } \\
\text { Anteroapical Infarct }\end{array}$ \\
\hline
\end{tabular}

Figure 1. Degree of MR graded on a scale of 0 to 4 (0, no MR; 4 , severe MR; see text) as determined by means of serial, transdiaphragmatic, quantitative, 2-dimensional echocardiography during infarction-induced remodeling in 5 ovine infarct models. The anteroapical (dashed line, filled squares), anterobasal (dashed line, filled triangles), laterobasal (dashed-dotted line, open triangles), posterobasal (solid line, filled circles), and posterobasal with annuloplasty (dotted line, open circles) groups are shown.

come of remodeling. Infarct location contributes to the anatomic manifestation of remodeling, with anteroapical infarcts leading to LV aneurysm and posterobasal infarcts causing progressive MR; the other basal infarcts result in a dilated cardiomyopathy without MR or LV aneurysm. The progressive and significant IMR that develops after the posterobasal infarct did not exacerbate any of the measured parameters of remodeling when compared with similarly sized infarcts in other locations within the 8-week study period. Ring annuloplasty was highly effective in preventing the development of IMR after the posterobasal infarct; however, it had no demonstrable effect on postinfarction ventricular remodeling during the 8 week study period. These data support the conclusion that IMR should be considered a manifestation of the remodeling process, which is dependent on infarct location but does not drive changes in ventricular size and shape. The data further suggest that the surgical correction of fully developed IMR might not affect ventricular remodeling and survival.

These findings, although seemingly counterintuitive, are consistent with clinical experience. The increasing incidence of IMR, combined with improved mitral valve repair techniques and a long history of surgical success in treating other valve diseases, has lead to heightened interest in and

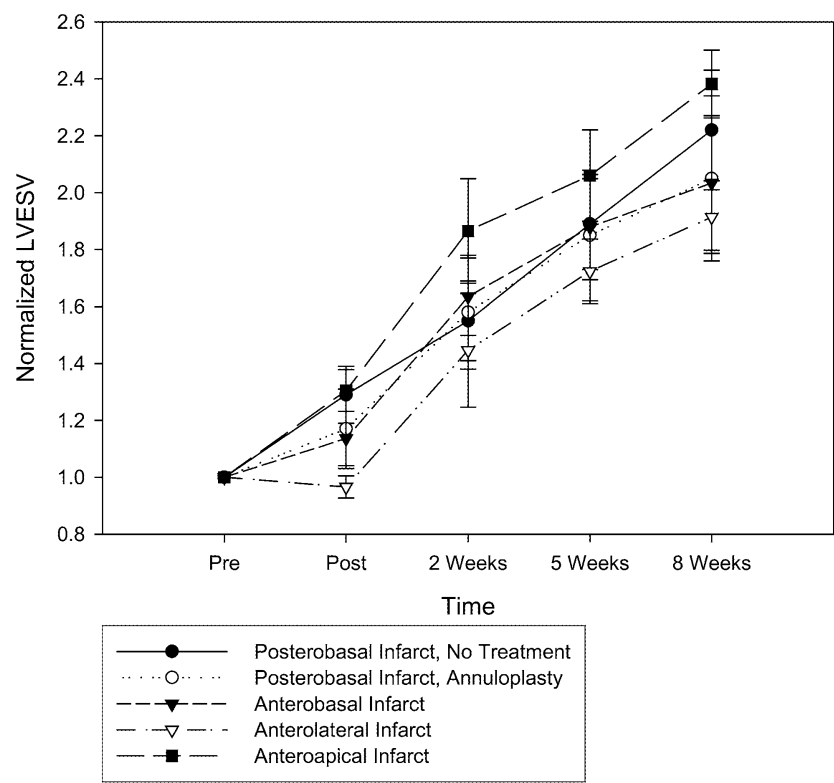

Figure 2. LVESV as determined by means of serial, transdiaphragmatic, quantitative, 2-dimensional echocardiography during infarction-induced remodeling in $\mathbf{5}$ ovine infarct models. The anteroapical (dashed line, filled squares), anterobasal (dashed line, filled triangles), laterobasal (dashed-dotted line, open triangles), posterobasal (solid line, filled circles), and posterobasal with annuloplasty (dotted line, open circles) groups are shown.

a very aggressive approach to IMR among surgeons and cardiologists. Most research has been focused on determining whether valve repair is preferable replacement or whether mild grades of IMR should be addressed surgically; however, the best and most recent clinical studies have failed to provide convincing evidence that the surgical treatment of IMR improves survival over medical management. $^{2-4}$

The failure of IMR to measurably contribute to adverse remodeling in these relatively short-term ovine models is indicative of the extreme impetus for remodeling that a moderately sized transmural MI imposes on the LV. It appears that the lessons learned regarding the indications for intervention in isolated mitral valve disease might not be directly applicable to patients with IMR.

This report builds on and adds to earlier work from our laboratory comparing untreated remodeling after posterobasal infarction with prophylactic ring annuloplasty or prophylactic ventricular restraint. In the posterobasal infarct model, ring annuloplasty is highly effective in preventing the development of IMR but has no demonstrable effect on remodeling. In contrast, ventricular wrapping reduced acute infarct expansion, preserved ejection fraction, and significantly improved measured parameters of postinfarction remodeling. Additionally, ventricular wrapping was almost as effective as ring annuloplasty in preventing the develop- 


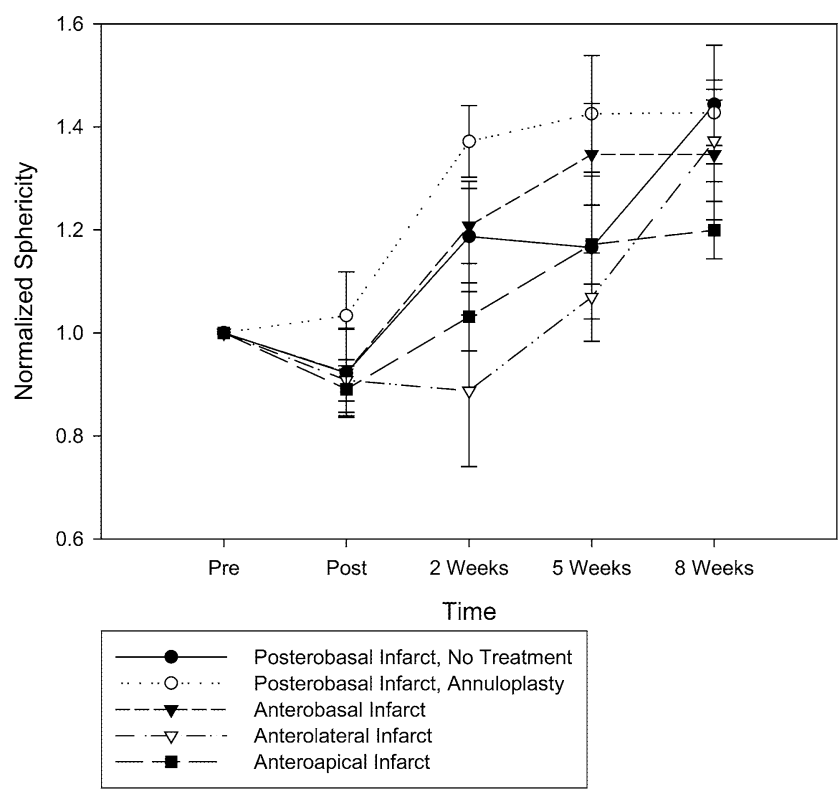

Figure 3. LV sphericity as determined by means of serial, transdiaphragmatic, quantitative, 2-dimensional echocardiography during infarction-induced remodeling in 5 ovine infarct models. The anteroapical (dashed line, filled squares), anterobasal (dashed line, filled triangles), laterobasal (dashed-dotted line, open triangles), posterobasal (solid line, filled circles), and posterobasal with annuloplasty (dotted line, open circles) groups are shown.

ment of IMR. ${ }^{5}$ These data led us to hypothesize that infarct expansion (stretching) is the critical inciting phenomenon that drives postinfarction remodeling. We further posited that well-recognized clinical phenomena, such as LV aneurysm and IMR, were likely just manifestations of remodeling that are dependent on infarct location but contribute little to perpetuating the remodeling process. By including the other infarct locations in this analysis, we were able to test these hypotheses and conclude that postinfarct remodeling is dependent on infarct size and occurs regardless of the infarct location, whether complicated by IMR or LV aneurysm. Therefore this study, in conjunction with our previous work, $5,13,14,17,18$ emphasizes infarct expansion as an important instigating mechanical phenomenon that drives remodeling and identifies it as a legitimate surgical target that might be exploited to prevent (rather than reverse) remodeling.

Recent laboratory ${ }^{19,20}$ and clinical $^{21}$ studies have shown that expansion (stretching) of a transmural MI initiates a progressive myopathic process in normally perfused myocardium. This phenomenon is initially localized to myocardium immediately adjacent to the infarct but extends during the remodeling process to convert contiguous and normally perfused myocardium into hypocontractile remodeled myocardium. The stretch-induced myopathic process has been

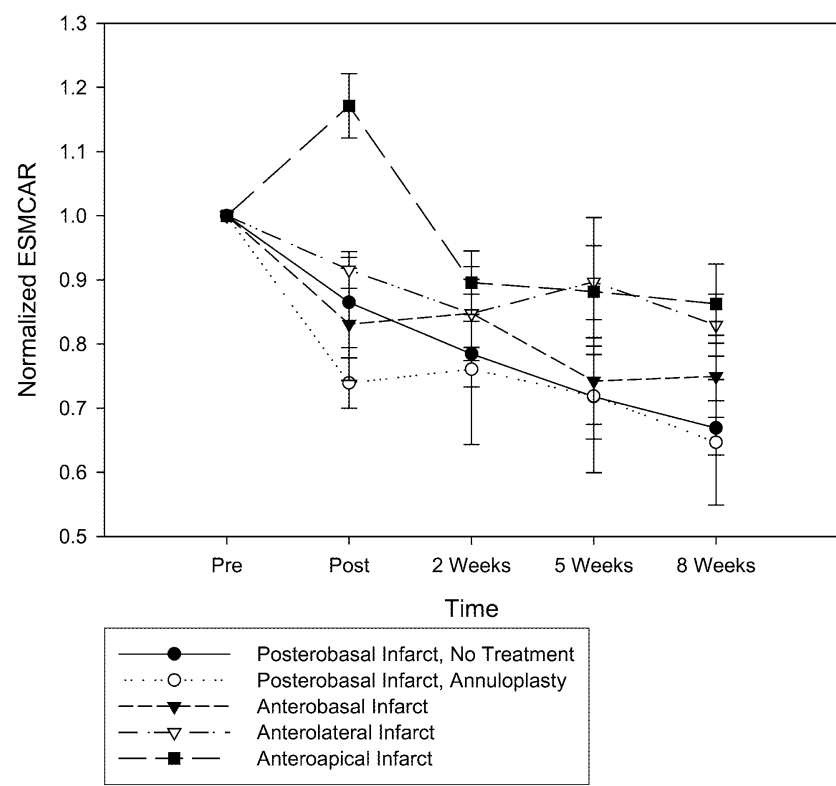

Figure 4. ESMCAR as determined by means of serial, transdiaphragmatic, quantitative, 2-dimensional echocardiography during infarction-induced remodeling in 5 ovine infarct models. The anteroapical (dashed line, filled squares), anterobasal (dashed line, filled triangles), laterobasal (dashed-dotted line, open triangles), posterobasal (solid line, filled circles), and posterobasal with annuloplasty (dotted line, open circles) groups are shown.

associated with myocyte apoptosis ${ }^{9}$ and disruption of the extracellular matrix caused by activation of matrix metalloproteinases. $^{22}$ The failure of surgical reshaping operations to improve survival in patients with ischemic cardiomyopathy strongly suggests that infarct-induced myopathy is very difficult to reverse once established. ${ }^{23-25}$ Using contrast echocardiography, Jackson and colleagues ${ }^{26}$ have demonstrated that early postinfarction geometric changes consistent with increased regional wall stress occur in the border region adjacent to infarcts undergoing early expansion and subsequent remodeling. A finite-element analysis by Guccione and coworkers ${ }^{19}$ confirms these findings and also demonstrates that once the myopathic process is fully developed, contractile function in nonischemic myocardium is impaired beyond what would be expected from changes in LV geometry and stress distribution. Therefore, early after infarction, loss of contractility is due to mechanical factors; as remodeling progresses, the geometric contribution (stress) to myocardial dysfunction is likely outstripped by the myopathic phenomenon that it initiates in normally perfused myocardium.

Although the results of this study are intriguing and provocative, there are limitations that warrant caution when generalizing the conclusions presented here to patients. It is not known whether the contribution of IMR to remodeling becomes progressively more important as infarct material 
properties change over time and infarct stretching becomes less of an impetus for remodeling. This question will be addressed by a longer and more clinically relevant follow-up period (ie, 6-12 months) of these ovine infarct models. Such experiments are ongoing in our laboratory. The current study did not address the affect of IMR on symptoms. It is widely believed that the surgical treatment of IMR improves heart failure symptoms and reduces subsequent hospitalization. Confirmation of this clinical impression would require a randomized clinical trial.

The data presented here contribute to a growing body of work that casts doubt on the ability of surgical procedures to affect longevity in patients with end-stage heart failure. $^{2-4,22-24,27}$ All currently available operations are designed to address the structural manifestations of fully developed remodeling and are dependent on the assumption that the remaining uninfarcted myocardium is capable of better contractile function once a more normal geometry is established. The veracity of this assumption is becoming more dubious.

\section{References}

1. Gorman RC, Gorman JH III, Edmunds LH Jr. Ischemic mitral regurgitation in cardiac surgery in the adult. In: Cohn LH, Edmunds LH Jr, editors. Cardiac surgery in the adult. New York: McGraw-Hill; 2003. p. 1751-70.

2. Gillinov AM, Wierup PN, Blackstone EH, Bishay ES, Cosgrove DM, White $\mathrm{J}$, et al. Is repair preferable to replacement for ischemic mitral regurgitation? J Thorac Cardiovasc Surg. 2001;122:1125-41

3. Grossi EA, Goldberg JD, LaPietra A, Ye X, Zakow P, Sussman M, et al. Ischemic mitral valve reconstruction and replacement: comparison of long-term survival and complications. J Thorac Cardiovasc Surg. 2001;122:1107-24

4. Diodato MD, Moon MR, Pasque MK, Barner HB, Moazami N, Lawton JS, et al. Repair of ischemic mitral regurgitation does not increase mortality or improve long-term survival in patients undergoing coronary artery revascularization: a propensity analysis. Ann Thorac Surg. 2004;78:794-9

5. Guy IV TS, Moainie SL, Gorman JH III, Jackson BM, Plappert T, Enomoto Y, et al. Prevention of ischemic mitral regurgitation does not influence the outcome of remodeling after posterolateral myocardial infarction. J Am Coll Cardiol. 2004;43:377-83.

6. Markovitz LJ, Savage EB, Ratcliffe MB, Bavaria JE, Kreiner G, Iozzo $\mathrm{RV}$, et al. Large animal model of left ventricular aneurysm. Ann Thorac Surg. 1989;48:838-45.

7. Gorman JH III, Gorman RC, Plappert T, Jackson BM, Hiramatsu Y, St. John-Sutton MG, et al. Infarct size and location determine the development of ischemic mitral regurgitation in the sheep model. J Thorac Cardiovasc Surg. 1998;115:615-22.

8. Moainie SL, Gorman JH III, Guy TS, Bowen FW III, Jackson BM, Plappert T, et al. An ovine model of postinfarction dilated cardiomyopathy. Ann Thorac Surg. 2002;74:753-60.

9. Llaneras MR, Nance ML, Streicher JT, Lima JA, Savino JS, Bogen DK, et al. Large animal model of ischemic mitral regurgitation. Ann Thorac Surg. 1994;57:432-9.

10. Llaneras MR, Nance ML, Streicher JT, Linden PL, Downing SW, Lima JA, et al. Pathogenesis of ischemic mitral insufficiency. J Thorac Cardiovasc Surg. 1993;105:439-42.

11. Gorman JH III, Gorman RC, Jackson BM, Enomoto Y, St John Sutton MG, Edmunds LH Jr. Annuloplasty ring selection for chronic ischemic mitral regurgitation: lessons from the ovine model. Ann Thorac Surg. 2003;76:1556-63.
12. Kelley ST, Malekan R, Gorman JH III, Jackson BM, Gorman RC, Suzuki Y, et al. Restraining infarct expansion preserves left ventricular geometry and function after acute anteroapical infarction. Circulation. 1999;99:135-42.

13. Moainie SL, Guy TS, Gorman JH III, Plappert T, Jackson BM, St John-Sutton MG, et al. Infarct restraint attenuates remodeling and reduces chronic ischemic mitral regurgitation after postero-lateral infarction. Ann Thorac Surg. 2002;74:444-9.

14. Schiller NB, Shah PM, Crawford M, DeMaria A, Devereux R, Feigenbaum $\mathrm{H}$, et al. Recommendation for the quantification of the left ventricle by two-dimensional echocardiography: American Society of Echocardiography Committee on Standards, Subcommittee on Quantitation of Two-Dimensional Echocardiograms. J Am Soc Echocardiogr. 1989;5:358-62.

15. Miyatake $\mathrm{K}$, Izumi S, Okamoto $\mathrm{M}$, Kinoshita $\mathrm{N}$, Asonuma $\mathrm{H}$, Nakagawa $\mathrm{H}$, et al. Semiquantitative grading of severity of mitral regurgitation by real-time two-dimensional Doppler flow imaging technique. J Am Coll Cardiol. 1986;7:82-8.

16. St. John Sutton MG, Pfeffer MA, Plappert T, Rouleau JL, Moye LA, Dagenais GR, et al. Quantitative two-dimensional echocardiographic measurements are major predictors of adverse cardiovascular events after acute myocardial infarction: the protective effects of captopril. Circulation. 1994;89:68-75

17. Enomoto Y, Gorman JH III, Moainie SL, Jackson BM, Parish LM, Plappert T, et al. Early ventricular restraint after myocardial infarction: the extent of the wrap determines the outcome of remodeling. Ann Thorac Surg. In press.

18. Moainie SL, Guy TS, Gorman JH III, Jackson BM, Plappert T, St John Sutton M, et al. Infarct restraint attenuates ischemic mitral regurgitation following posterolateral infarction. Ann Thorac Surg. 2002;74: 444-9.

19. Guccione JM, Moonly SM, Moustakidis P, Costa KD, Moultron MJ, Ratcliffe MB, et al. Mechanism underlying mechanical dysfunction in the border zone of left ventricular aneurysm: a finite element model study. Ann Thorac Surg. 2001;71:654-62.

20. Jackson BM, Gorman JH III, Moainie SL, Guy TS, Narula N, Narula $\mathrm{J}$, et al. Extension of borderzone myocardium in postinfarction dilated cardiomyopathy. J Am Coll Cardiol. 2002;40:1160-7.

21. Narula J, Dawson MS, Singh BK, Amanullah A, Acio ER, Chaudhry FA, et al. Noninvasive characterization of stunned, hibernating, remodeled and nonviable myocardium in ischemic cardiomyopathy. J Am Coll Cardiol. 2000;36:1913-9.

22. Wilson EM, Moainie SL, Baskin JM, Lowry AS, Deschamps AM, Mukherjee R, et al. Region and species specific induction of matrix metalloproteinases occurs with post-myocardial infarction remodeling. Circulation. 2003;107:2857-63.

23. Couper GS, Bunton RW, Birjiniuk V, DiSesa VJ, Fallon MP, Collins $\mathrm{JJ} \mathrm{Jr}$, et al. Relative risks of left ventricular aneurysmectomy in patients with akinetic scars versus true dyskinetic aneurysms. Circulation. 1990;82(Suppl):IV248-56.

24. Franco-Cereceda A, McCarthy PM, Blackstone EH, Hoercher KJ, White JA, Young JB, et al. Partial left ventriculectomy for dilated cardiomyopathy: is this an alternative to transplantation? J Thorac Cardiovasc Surg. 2001;121:879-93.

25. Dor V, Sabatier M, Di Donato M, Montiglio F, Toso A, Maioli M. Efficacy of endoventricular patch plasty in large postinfarction akinetic scar and severe left ventricular dysfunction: Comparison with a series of large dyskinetic scars. J Thorac Cardiovasc Surg. 1998;116:50-9.

26. Jackson BM, Gorman JH III, Salgo IS, Moainie SL, Plappert T, St John-Sutton M, et al. Border zone geometry increases wall stress after myocardial infarction: contrast echocardiographic assessment. Am J Physiol Heart Circ Physiol. 2003;284:H475-9.

27. Gorman RC, Jackson BM, Gorman JH III. Potential role of ventricular compressive therapy. Surg Clin North Am. 2004:84:45-59.

\section{Discussion}

Dr Frank W. Sellke (Boston, Mass). Doesn't this go against conventional wisdom and common sense. That is, if you have MR, you are going to have volume overload, and that has to contribute, 
at least in some way, to the geometry of the ventricle over time. Am I missing the point?

If you have a leaky valve, you are going to have different pressures within the heart, and you tend to have volume overload. How can that not contribute to the remodeling of the heart?

Dr Moainie. I think the pathology is located in the myocardium. Although there has to be some effect of the regurgitation in terms of volumes, it is so minuscule in terms of its effect that the true pathology lies in the myocardium and in the infarct-induced remodeling, and the variable is so minor that it really does not affect the results of the remodeling.

Dr Frank A. Pigula (Boston, Mass). Did you look at the left atrial dimensions at all, or did you assess left atrial function?

Dr Moainie. We did not focus on left atrial function. We looked at ventricular function and overall LV function.

Dr Bradley S. Allen (Houston, Tex). One question about your controls. Like Dr Sellke, I would have imagined that if you had mitral valve regurgitation, you would get some sort of volume overload and ventricular remodeling.

The question, therefore, is what happens if you just cause mitral valve regurgitation in hearts for 8 weeks without an infarction. Does the ventricle get bigger? If indeed there is ventricular enlargement (remodeling) in 8 weeks with just MR (no infarction), then it would follow that you are correct and the pathology is all in the ventricle. However, if the ventricular enlargement is minimal after 8 weeks of MR alone, then it might be that your time frame is too short to allow these conclusions because the MR has not had sufficient time to dilate the heart.

I would also echo what Dr Pigula was saying about left atrial size. If the MR increases left atrial size, this might lead to arrhythmias, and therefore it might still be important to correct the MR.

Dr Moainie. In response to your first question, the second set of experiments is more focused at addressing that issue. Because the only difference between those 2 groups of animals is the presence of MR, that is the only variable that is different. They have the identical infarct. Therefore, you would think that if the MR was the variable that was contributing - if it had any effect on the changes in volumes - that the group that had a prophylactic annuloplasty ring and therefore had no MR during the entire course of the study should, by virtue of that, have a decreased amount of dilatation. There should be some difference that is demonstrable at 8 weeks. Even though it is only 8 weeks, there should be a demonstrable change.

In terms of the time course, you can see that the control group does double at 8 weeks. Therefore, clearly the 8 weeks is long enough to demonstrate the pathology that occurs with ischemic disease. However, eliminating the MR made no difference. Therefore, it is hard to imagine that even if you followed those animals out for 16 weeks that anything would change in that course.

In terms of the arrhythmia issue, that is something that obviously should be addressed separately, but that was not the focus of this study.
Dr W. Randolph Chitwood, Jr (Greenville, NC). Have you done a similar type of study in which you induced ischemia alone and did not allow a true infarction to develop?

Dr Moainie. We have not. One of the advantages of sheep is that they have no collateral circulation, and therefore they are very pure models of infarction. But because they have no collaterals, for creating ischemia, you have to do this with amyloid constrictors or something other than localized infarcts, and we have not really delved into that area.

Dr Chitwood. So the clinical call here is that we are treating the symptoms of MR and not anything else. Is that the call?

Dr Moainie. I think the results of this study really beg for a clinical study that would look at just the question that you have posed, a study that would look at a randomized clinical study of treatment of IMR and not treatment of IMR in a group of patients to see whether, in fact, we are affecting survival at all or if we are purely operating on symptoms.

Dr Paul Kurlansky (Miami Beach, Fla). It is a very interesting study and a very provocative one. But I am a little concerned about too readily drawing the wrong clinical implications from it.

I think one thing that you are clearly dealing with here is the evolution of a cardiomyopathy and what the factors that cause remodeling might be, as it were. What is the remodeling process, and what are the key factors in the evolution of the remodeling process?

What it seems that you have shown fairly convincingly is that MR is not a key factor in the initial ischemic remodeling process. Whether or not MR has an aggravating or accelerating effect in the long term, once somebody has a cardiomyopathic process, it is a totally different issue.

These animals were followed up for 8 weeks. There are significant clinical data that seem to indicate that patients who already have established cardiomyopathy and have MR have a severely worse prognosis than those with cardiomyopathy who do not have MR. Therefore, it might be that although the MR is not key in the evolution of the cardiomyopathy, in the maintenance and long term and evolution and prognosis and ability to treat it, it might be a key factor. I also think that is something that is important to try to distinguish in the long-term evaluation of your results.

Dr Moainie. There are a number of ways one can look at the issue that you bring out. One of the ways that I look at it is that the presence of IMR in a group of patients with heart failure is simply a manifestation of the severity of their disease. That it, in fact, is kind of a chicken-or-egg phenomena. That it is not so much the cause of their failure, but it is just a manifestation of how severe their disease, in fact, is.

And something that would suggest that this is, in fact, the case, is that when you look at the survival data for surgery for IMR in the presence of failure, the survival data are not significantly different than those of heart failure in general. Therefore I think that, combined with the results of this study, this would suggest an indication to perform more intensive clinical investigation of this topic. 